\title{
Müllerian Vaginal Cyst Mimicking Hysterocele
}

\author{
Aude Nessi ${ }^{1 *}$, JY Meuwly ${ }^{2}$ and C Achtari ${ }^{1}$ \\ ${ }^{1}$ Department of Gynecology, Centre Hospitalier Universitaire Vaudois, Switzerland \\ ${ }^{2}$ Department of Radiology, Centre Hospitalier Universitaire Vaudois, Switzerland
}

Submission: June 07, 2019; Published: June 17, 2019

*Corresponding author: Aude Nessi, Gynecologist, Department of Obstetrics and Gynecology, University Hospital of Lausanne, Maternity-CHUV, 1011 Lausanne, Switzerland

\begin{abstract}
Müllerian and Gartner duct cysts are rare embryological remnants of the vaginal wall. Their sizes may vary from one to several centimeters. Dyspareunia, pelvic pain, pressure, bulging mass and urinary incontinence are the most frequent presenting symptoms associated with these vaginal cysts. The purpose of this report is to present a case of hysterocele associated with Müllerian vaginal cyst.
\end{abstract}

Keywords: Pelvic Organ Prolaps; MRI; Mullerian cyst; Sacrocolpopexy

\section{Introduction}

Few case reports describe vaginal cyst presenting as cystocele [1-7]. Prevalence of vaginal cyst is 1 in 200 women [8]. Vaginal cysts have various etiologies: in decreasing order of incidence: Müllerian cysts, epidermal inclusion cysts, Gartner's cysts, bartholin's gland cysts, endometriosic vaginal cysts [9] and urethral and para-urethral origins, followed by a few other rare lesions [8]. Müllerian and Gartner duct cysts are rare embryological remnants. The uterus, cervix and upper vagina develop at 8 weeks of gestation with distal fusion of the Müllerian (paramesonephric) ducts. In females the Wolffian (mesonephric) ducts regress and their remnants are known as Gartner's duct, which can potentially lead to Gartner's cysts $[2,8]$.

Müllerian cysts arise from persistence of pseudostratified columnar epithelium during its replacement with squamous epithelium. This epithelium can persist anywhere in the vagina but Müllerian cysts are generally located anterolaterally near the vaginal fornix $[1,2,8]$. Their size varies generally between $1 \mathrm{~cm}$ to $7 \mathrm{~cm}$ but can sometimes be much bigger. $40 \%$ of the cystic vaginal masses of embryologic origin are Müllerian cysts $[8,9]$. Dyspareunia, pelvic pain, pressure, bulging mass and urinary incontinence or obstruction are the most frequent presenting symptoms associated with vaginal cyst [8].

Radiologic imaging can help identifying the localization of cysts in relation to adjacent organs and other associated urogenital anomalies $[7,10]$.

\section{Objective}

This is a case report describes a large Müllerian cyst presenting like a C3H2R2 vaginal prolapse.

\section{Case Study}

A 41-year-old Para 3, otherwise healthy woman, presented with C3H2R2 prolapse according to POP-Q testing, in aggravation since her second pregnancy. She had no urinary incontinence complaints. A conservative treatment with pessary was tried but was not found to be satisfactory. Five months before she was referred to us, she reported pain in the right iliac fossa and underwent a CT scan, that described an $80 \times 40 \times 30 \mathrm{~mm}$ right pelvic homogenous fluid collection of unknown origin (Figure 1). A diagnostic laparoscopy was performed, and the only finding was a slight retroperitoneal bulging near the right uterosacral ligament, no surgical treatment was attempted, and the surgeon concluded to a venous vs lymphatic stasis. One month later, MRI imaging was performed for persisting pelvic pain and was unremarkable apart from the pelvic organ prolapse: no fluid-like collection was described (Figure 2). She was referred to our center for surgical management of the prolapse. Clinical exam confirmed C3H2R2 prolapse according POP-Q testing. She underwent laparoscopic sacrocolpopexy with concomitant subtotal hysterectomy and salpingectomy. During the surgery the slight peritoneal bulging was seen again, but not removed, because we were afraid of venous stasis. The 6-weeks postoperative clinical exam showed persistent cystocele with no 
recurrent hysterocele. Bulging appeared 2 weeks postoperatively and pain reappeared. A repeat MRI highlighted the presence of a large cyst of vaginal origin (Figure 3 ). The cyst was punctured, with aspiration of clear brownish fluid allowing a decrease of pain. We scheduled a surgical total cyst excision per vaginam (Figure 4). At her postoperative visit, the patient reported some dyspareunia. Examination presented well healed incisions and a good anterior, apical and posterior support. Histology of the lesion revealed a Müllerian cyst lined by endocervical cells, secreting mucinous fluid inside this cyst. A detailed review of the radiologic exams concluded that it was a cyst of vaginal origin with wandering fluid passing from the vagina to the right posterior fornix through an hourglass like passage located next to the cervix, at the origin of the prolapse (Figure 2).
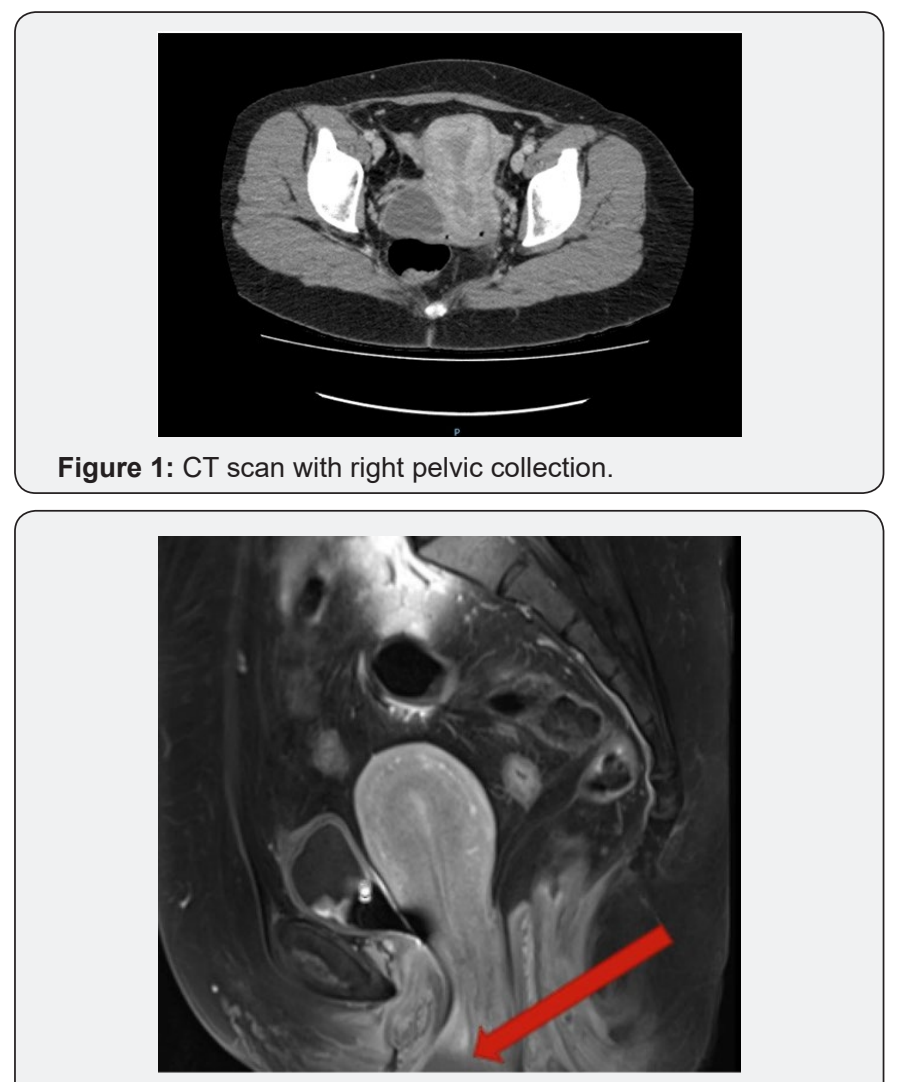

Figure 2: MRI one month after diagnostic laparoscopy showing POP with no collection, MRI before sacrocolpopexy showing cyst outside of vagina.

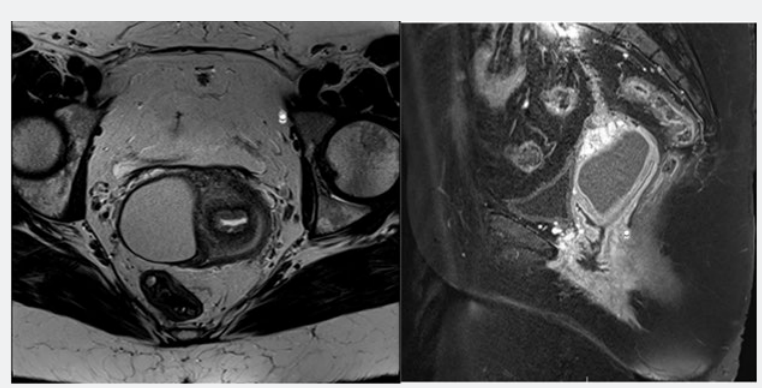

Figure 3: MRI post sacrocolpopexy with large cyst of vaginal origin.

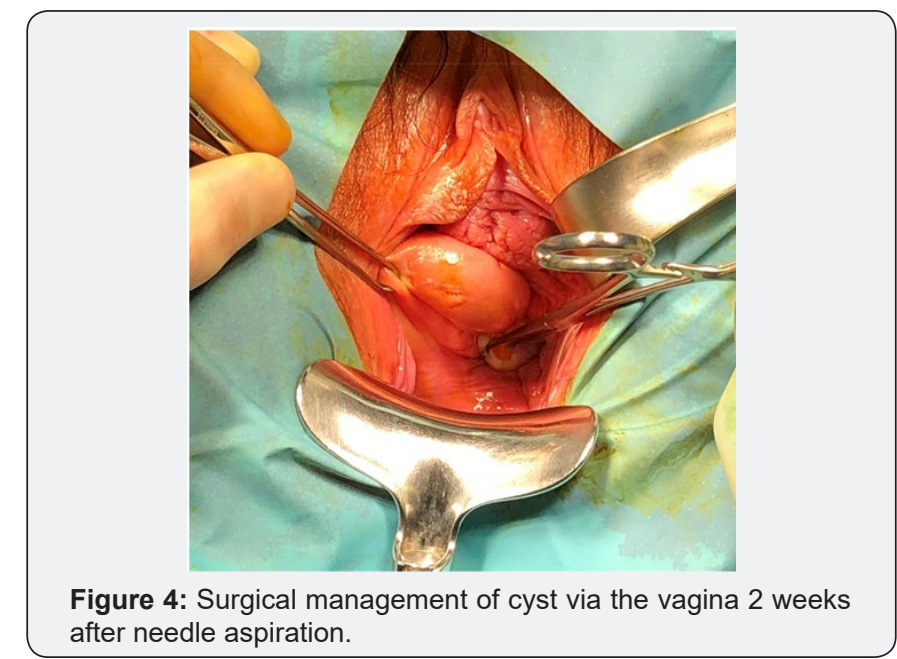

after needle aspiration.

\section{Discussion}

Vaginal wall cysts are usually seen in the third and fourth decades [4,8], their presence is noted incidentally during physical exams or radiologic imagery. It can be symptomatic when of large size: in our case the patient's complaint was vaginal pressure and discomfort, right iliac fossa pain, and dyspareunia, which are like POP symptoms [12]. Because MRI did not describe any fluid collection, we assumed it was simply a POP. In our knowledge, there are a dozen reported cases of vaginal cyst mimicking cystocele and one accompanied with cervical elongation [1-7], but this is the first reported case of vaginal cysts associated with hysterocele.

Mullerian and Gartner cysts are benign tumors, but malignancy must be considered. Lee reported adenocarcinoma arising in a Mullerian vaginal cyst [13]. In literature there are very rare reported cases of malignant vaginal cysts, but even with an asymptomatic and small cyst this eventuality should be considered.

Cysts should be characterized by radiologic investigations, Ultrasound and computed tomography (CT) are helpful to define the cystic mass $[7,11,12]$. Magnetic Resonance Imaging (MRI) is the gold standard to characterize surrounding tissues and define origin and extent of the pelvic mass. In our case, the first exam was a CT. The radiologist described a pelvic homogenous fluid collection of unknown origin. Use of MRI might have allowed better characterization of the müllerian vaginal cyst.

Management of vaginal cysts depends on the associated symptoms. In the cases of incidental finding of asymptomatic vaginal cysts, conservative treatment with observation may be an option [14] Vaginal cyst discharge by fluid aspiration reduces volume and pain as in one case describing a vaginal cyst discovered during pregnancy. This fluid aspiration permitted vaginal birth [2]. In 1991 Raddo [15] described a non- surgical management with use of $5 \%$ tetracycline sclerotherapy after cyst aspiration with good results. 
Conventionally the management is surgical including marsupialization in rare cases and more often complete surgical excision [14]. In our case after sacrocolpopexy, we discharged the cyst and a few days later we performed an excision with good anatomic results.

\section{Conclusion}

This case report highlights the need to correlate radiologic to physical exams by one referent. In our knowledge, no case report has ever described hysterocele associated with Müllerian vaginal cyst. However, it is not possible to definitively conclude if the cyst was mimicking a vaginal prolapse or whether it was a true prolapse associated with wandering content of a large Mullerian cyst.

\section{References}

1. Lallar M, Nandal R, Sharma D, Shastri S (2015) Large posterior vaginal cyst in pregnancy. BMJ Case Report 2015.

2. Arumugam AV, Kumar G, Si LK, Vijayananthan A (2007) Gartner duct cyst in pregnancy presenting as a prolapsing pelvic mass. Biomed Imaging Interv J 3(4): e46.

3. Davidson ERW, Barber MD (2017) A Gartner Duct Cyst Masquerading as Anterior Vaginal Prolapse. Obstetrics and Gynecology 130(5): 10391041.

4. Dilbaz B, Sengül O, Dede S, Yerebasmaz N, Akkurt O (2014) Prolapsing vaginal Mullerian cyst with cervical elongation mimicking cystocele. J Obstet Gynaecol 34(2): 212-213.

5. Toz E, Sanci M, Cumurcu S, Ozcan A (2015) Müllerian Cyst of the Vagina Masquerading a Cystocele Case Reports in Obstetrics and Gynecology 2015(376834): 3.
6. Inoncêncio G, Azevedo S, Braga A, Carinhas MJ (2013) Large Gartner cyst. BMJ Case report.

7. Hwang JH, Oh MJ, Lee NW, Hur JY, Lee KW, et al. (2009) Multiple vaginal mullerian cysts: a case report and review of literature. Arch Gynecol Onstet 280(1): 137-139.

8. Eilber KS, Raz S (2003) Begnign cystic lesions of the vagina: a literature review. J Urol 170(3): 717-722.

9. Prdhan S, Tobon H (1986) Vaginal cysts: a clinicalpathological study of 41 cases. Int J Gynecol Pathol 5(1): 35-46.

10. Dwyer PL, Rosamalia A (2005) Congenital urogenital anomalies that are associated with the persistence of Gartner's duct: a review. Am J Obstet Gynecol 195(2): 354-359.

11. Tiwari U, Relia N, Shailesh F, Kaushik C (2014) Gartner Duct Cyst: CT and MRI findings. J Obstet Gynaecol India 64(Suppl 1): 150-151.

12. Elsayes KM, Narra VR, Dillman JR, Velcheti V, Hameed O, et al. (2007) Vaginal masses: magnetic Resonance Imaging features with Pathologic correlation. Acta Radiol 48(8): 921-933.

13. Lee KS, Park KH, Lee S, Kim JY, Seo SS (2005) Adenocarcinoma arising in a vaginal mullerian cyst: a case report. Gynecol Oncol 99(3): 767769 .

14. Cope AG, Laughlin-Tommaso SK, Famuyide AO, Gebhart JB, Hopkins MR, et al. (2017) Clinical manifestations and outcomes in surgically managed Gartner duct cysts. J Minim Invasive Gynecol 24(3): 473-477.

15. Abd-Rabbo MS, Atta MA (1991) Aspiration and tetracycline sclerotherapy: a novel method for management of vaginal and vulval Gartner cysts. Int J Gynaecol Obstet 35(3): 235-237.

\section{Your next submission with Juniper Publishers will reach you the below assets}

- Quality Editorial service

- Swift Peer Review

- Reprints availability

- E-prints Service

- Manuscript Podcast for convenient understanding

- Global attainment for your research

- Manuscript accessibility in different formats

( Pdf, E-pub, Full Text, Audio)

- Unceasing customer service

Track the below URL for one-step submission https://juniperpublishers.com/online-submission.php 